\title{
Carriage of intestinal protozoal cysts in homosexuals
}

\author{
A T L CHIN AND A GERKEN \\ From the Department of Medical Microbiology, Charing Cross Hospital, Fulham Palace Road, \\ London W6 8RF
}

SUMMARY A total of 83 male homosexuals were studied to ascertain the carriage of intestinal protozoal cysts. The homosexual group had a significantly $(p<0 \cdot 0005)$ higher prevalence than a control group. One or more types of protozoa were found in 33 homosexuals. The carriage of intestinal protozoal cysts was associated with particular sexual practices and promiscuity, but not with symptomatic bowel disorders. The possible implications of the carriage of these cysts are discussed.

\section{Introduction}

Since the early 1970 s there has been an increasing number of reports of enteric pathogens in male homosexuals. These organisms are presumably transmitted through the faeco-oral route by sexual practices such as fellatio and anilingus. After their first observation in the United States ${ }^{12}$ and Canada, ${ }^{3}$ infections with Entamoeba histolytica and Giardia lamblia were described in male homosexuals in Glasgow ${ }^{4}$ and London. ${ }^{5}$ Isolated cases of Enterobius vermicularis have also been reported in homosexuals in other parts of Great Britain. ${ }^{67}$ The transmission of other enteric pathogens such as Salmonella typhi and Shigella spp among homosexuals has also been recorded. $8-11$

We prospectively studied 83 male homosexuals attending the department of genitourinary medicine at this hospital and $\mathbf{4 3}$ male controls to determine the prevalence of intestinal protozoal cysts and the relation between the carriage of cysts and symptoms, certain sexual practices, and history of other sexually transmitted diseases (STD).

\section{Patients and methods}

The 83 male homosexuals and 43 controls participated voluntarily in this study. Medical students and laboratory technicians were chosen as controls because they were considered to be a cross section of the male population, although not necessarily an entirely heterosexual one. ${ }^{12} \mathrm{We}$ could not find a suitable control group of male

Address for reprints: Dr A T L Chin, Department of Medical Microbiology, St Helier Hospital, Wrythe Lane, Carshalton, Surrey

Accepted for publication 30 November 1983 heterosexuals from patients attending the clinic because some patients who presented with anal warts were suspected of giving a false sexual preference and many others were reluctant to submit a stool specimen.

Both groups were asked to complete a questionnaire, although that for the control group excluded the questions relating to sexual history. The information obtained was age, travel history, diarrhoea (defined here as the passage of three unformed stools in 24 hours), abdominal pain and flatulence in the preceding three months, the average number of sexual partners each week, and preferred sexual acts. Previous episodes of STD including syphilis, gonorrhoea, non-specific urethritis and proctitis, genital herpes, anogenital warts, and the presence of hepatitis B surface antibodies (anti-HBs) were recorded from the notes of 74 of the patients.

The homosexuals were routinely screened for gonorrhoea and syphilis, and all participants were asked to submit a faecal specimen. The stools were screened for ova, cysts, and parasites by a formolether concentration method. The species of any entamoeba found was confirmed at the Hospital for Tropical Diseases, London. Routine culture for Salmonella spp, Shigella spp, and Campylobacter spp was also performed.

The $\chi^{2}$ test with Yates's correction was used in the statistical analysis of the data.

\section{Results}

The mean age of the homosexuals was 33 (range 22-54) years and of the controls 25 (range 17-44) years. Of the 83 homosexuals, 63 were born and lived in the United Kingdom, and the remaining 20 had spent varying periods abroad. No relation was noted 
between the presence of cysts and foreign travel in either the homosexuals or the controls. Intestinal protozoal cysts were significantly $(p<0.0005)$ more common in the homosexuals, $33(40 \%)$ of whom had cysts compared with two $(4 \cdot 7 \%)$ controls. Of the 33 homosexuals who carried cysts, seven had two types, eight had three, and one had four. The table shows that $E$ histolytica was present in 10 homosexuals, and $G$ lamblia in seven. Cysts most frequently found were those of Endolimax nana and Entamoeba coli, which are non-pathogenic. $E$ coli was found twice in the control group, once in conjunction with Trichuris trichiura.

TABLE Intestinal protozoa in the stools of male homosexuals compared with controls

\begin{tabular}{lll}
\hline & $\begin{array}{l}\text { Homosexuals } \\
(n=83)\end{array}$ & $\begin{array}{l}\text { Controls } \\
(n=43)\end{array}$ \\
\hline Entamoeba coli & 21 & 2 \\
Endolimax nana & 18 & 0 \\
Entamoeba histolytica & 10 & 0 \\
Giardia lamblia & 7 & 0 \\
Entamoeba hartmanni & 4 & 0 \\
Iodamoeba bütschlii & 3 & 0 \\
Trichuris trichiura & 0 & 1 \\
\hline
\end{tabular}

Although gastrointestinal complaints were more common in the homosexuals even in those without cysts $(p<0.05)$, no correlation could be found between symptoms and the presence of cysts, including those of varieties or species normally considered to be pathogenic. There was no relation between symptoms and a history of rectal gonorrhoea or non-specific proctitis; 21 of the 32 symptomatic patients and 19 of the 42 asymptomatic patients had had rectal gonorrhoea, non-specific proctitis, or both $(p>0.05)$. Thirty five homosexuals had suffered from at least one episode of diarrhoea in the three months before attending the clinic. During their attendance at the clinic 10 complained of loose bowel motions, 30 of flatulence, and 17 of abdominal pain.

Seventy homosexuals had a history of gonorrhoea or non-specific urethritis. There was a significantly higher prevalence of cysts in the 24 who were considered to be promiscuous (with two or more sexual partners a week), 15 of whom had cysts in the stools and nine did not $(p<0.02)$. In this group of homosexuals, 18 had histories of gonorrhoea and 19 of non-specific urethritis, compared with 25 histories of gonorrhoea and 23 of non-specific urethritis among the $\mathbf{4 6}$ non-promiscuous homosexuals. Sexual activity with two or more sexual partners at the same time, was recorded in 31 homosexuals, 18 of whom had intestinal cysts and 13 did not $(p<0 \cdot 02)$. Of the 74 patients with histories of STD, 24 of the 30 with cysts and 22 of the 44 without cysts had had gonorrhoea $(\mathrm{p}<0 \cdot 02)$. Oroanal sex was practised by 42 homosexuals, 23 of whom had detectable cysts and the remainder did not $(p<0 \cdot 01)$. There was no correlation between the presence of anti-HBs and promiscuity $(p>0.05)$, the presence of anti-HBs and the carriage of protozoal cysts $(p>0.05)$, or the presence of cysts and syphilis $(p>0 \cdot 05)$. No salmonella, shigella, or campylobacter were isolated from the stools of either group.

\section{Discussion}

A high prevalence of intestinal protozoal cysts has been reported in male homosexuals, but the relevance of them to disease has not yet been clarified. One study has shown a correlation between symptoms and cysts but only when more than one type, including $G$ lamblia, was present. ${ }^{3}$ Although our study showed a high prevalence of cysts and a significantly higher prevalence of gastrointestinal symptoms in the homosexual group, the two factors were not related. Even when types usually considered to be pathogens, such as $G$ lamblia, were found or when more than one genus was present, no association was shown between symptoms and the presence of cysts. Three patients who had both $E$ histolytica and $G$ lamblia were asymptomatic. However cyst carriage may have other important implications. The presence of cysts including non-pathogenic varieties, such as $E$ coli, may indicate the presence of other types of cyst including pathogenic genera and bacterial pathogens. As $40 \%$ of our homosexual group were cyst carriers, many may also have harboured other enteric pathogens. The prevalence might have been even higher if purged ${ }^{2}$ or repeated ${ }^{13}$ stool specimens had been examined. Why homosexuals appear to have a high prevalence of cysts in uncertain. We thought that it may have been related to foreign travel but were unable to show an association. It is more likely that faeco-oral contamination is responsible. We certainly found a high prevalence of cysts in those who had multiple sexual partners at the same time or within a short period and in those who had oroanal contact.

No association could be found between the gastrointestinal symptoms and gonococcal and non-specific proctitis, which confirms a recent study which showed that gastrointestinal symptoms do not differentiate between patients with and without proctitis. ${ }^{14}$ Of homosexuals with symptomatic proctitis, however, $80 \%$ may have anorectal infections due to Neisseria gonorrhoeae, herpes simplex virus, Chlamydia trachomatis, and Treponema pallidum. ${ }^{15}$

The role of $E$ histolytica in diarrhoea is interesting. Only certain groups of this genus are associated with 
clinical amoebiasis. Homosexuals seem to carry the non-pathogenic varieties, ${ }^{5}$ which may account for the lack of symptoms and perhaps the lack of correlation with travel. The types of $E$ histolytica that normally produce symptoms may occur only in tropical and subtropical regions. Recent reports of a dramatic increase in symptomatic amoebiasis in San Francisco, however, suggest that either pathogenic varieties have been introduced into that community, or immunosuppression may have a role. ${ }^{16}$ Symptomatic amoebiasis and giardiasis are more likely to occur in immunodeficient people, and certain groups of male homosexuals have been shown to have an appreciable suppression of their immune function. ${ }^{17}$ Only one of the seven homosexuals in our group who had $G$ lamblia had diarrhoea. $E$ histolytica has also been found to have immunosuppressive activity, ${ }^{18}{ }^{19}$ and has recently been proposed as having a role in the acquired immune deficiency syndrome (AIDS). ${ }^{16}$

Many questions regarding the pathogenic role of intestinal protozoa remain unanswered. Further investigations are needed into the pathogenesis of symptomatic intestinal amoebiasis in homosexuals. Even though $E$ histolytica with pathogenic markers is associated with symptomatic infection in people with normal immune function, such markers may not be necessary for symptomatic disease in immunocompromised homosexuals. Meanwhile, screening for protozoa should be encouraged in all homosexual patients with diarrhoea. It remains to be decided whether finding these cysts should alert the clinician to the possibility that the individual is immunosuppressed.

We thank Dr J L Fluker and Dr B A Evans for allowing us to study their patients, and the London Hospital for Tropical Diseases for its help. The work is part of an MSc thesis accepted by the University of Surrey.
References

1. Kazal HL, Sohn N, Carrasco JI. The gay bowel syndrome: clinico-pathological correlation in 260 cases. Ann Clin Lab Sci 1976; 6: 184-92.

2. William DC, Shookhoff HB, Felman YM, De Ramos SW. High rates of enteric protozoal infections in selected homosexual men attending a venereal disease clinic. Sex Transm Dis 1978; 5: 155-7.

3. Keystone JS, Keystone DL, Proctor EM. Intestinal parasitic infections in homosexual men; prevalence, symptoms and factors in transmission. Can Med Assoc J 1980;123:512-4.

4. McMillan A. Intestinal parasites in homosexual men. Scott Med J 1980; 25: 33-5.

5. Sargeaunt PG, Oates JK, Maclennan I, Oriel JD, Goldmeier D. Entamoeba histolytica in male homosexuals. Br J Vener Dis 1983;59: 193-5.

6. McMillan A. Threadworms in homosexual males. Br Med J 1978;i: 367.

7. Waugh MA. Threadworm infestation in homosexuals. Transaction of the St Johns Hospital Dermatological Society 1972;58:224-5.

8. Dritz SK, Braff EH. Sexually transmitted typhoid fever. $N$ Engl J Med 1977; 296: 1359-60.

9. Dritz SK, Back AF. Shigella enteritis venereally transmitted disease. N Engl J Med 1974;291:1194.

10. Drusin LM, Genvent G, Topf-Olstein B, Levy-Zombek E. Shigellosis, another sexually transmitted disease. Br J Vener Dis 1976;52: 348-50.

11. Dritz SK, Ainsworth TE, Back AF, et al. Patterns of sexually transmitted diseases in a city. Lancet 1977; ii: 3-4

12. Kinsey AC, Pomeroy WB, Martin CE. Sexual behaviour in the human male. London and Philadelphia: Saunders, 1948.

13. Sawitz WG, Faust EC. The probability of detecting intestinal protozoa by successive stool examinations. American Journal of Tropical Medicine 1942;22:131-6.

14. McMillan A, Gilmour HM, Slatford K, McNeillage GJC Proctitis in homosexual men. Br J Vener Dis 1983;59:260-4.

15. Quinn TC, Stamm WE, Goodell SE, et al. The polymicrobial origin of intestinal infections in homosexual man. $N$ Engl $J$ Med 1983;309:576-82.

16. Pearce RB. Intestinal protozoal infection and AIDS. Lancet 1983 ;ii: 51 .

17. Kornfeld H, Vande Stouwe RA, Lange M, Reddy MM, Grieco MH. T-lymphocyte subpopulations in homosexual men. $N$ Engl J Med 1982;307:729-31.

18. Diamanstein T, Klos M, Gold D, Hahn H. Interaction between Entamoeba histolytica and the immune system I: mitogenicity of Entamoeba histolytica extracts for human peripheral T lymphocytes. J Immunol 1981; 126: 2084-6.

19. Mizerski J, Chartrand S, Gajlpeczalska K. Con A induced suppressor cells in man I: induction and characterization of suppressor cells. Immunobiol 1981; 158:270-81. 